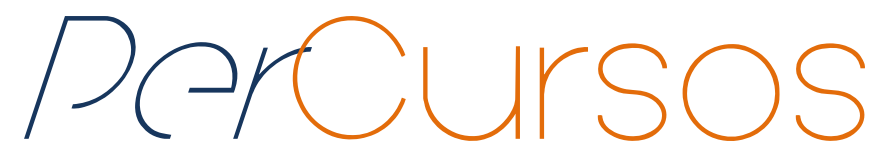

\title{
Educação de Jovens e Adultos no Brasil Uma entrevista com a professora Maria Clara Di Pierro
}

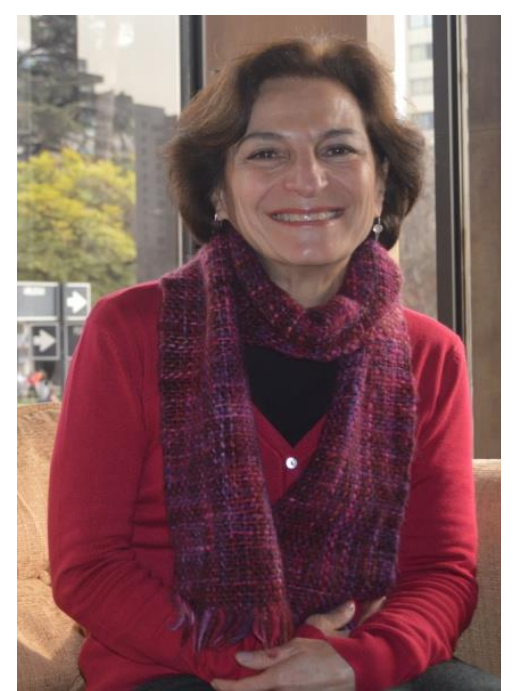

A professora Maria Clara Di Pierro é pesquisadora na área da Educação de Jovens e Adultos no Brasil. Graduada em Geografia pela Faculdade de Filosofia, Letras e Ciências Humanas da Universidade de São Paulo, Mestre e Doutora em Educação. É professora na Faculdade de Educação da Universidade de São Paulo, atuando na Graduação e na PósGraduação. Em 2011-2012 realizou estágio pós-doutoral no Teachers

\section{Entrevistadora}

Rita de Cássia Pacheco Gonçalves Doutora em Educação pela Universidade de Lisboa -

Portugal. Professora da Universidade do Estado de Santa Catarina - UDESC. Brasil ritacassiagon@gmail.com

Columbia University. Sua experiência tem ênfase em Educação de Jovens e Adultos. Atua no Fórum de Educação de Jovens e Adultos do Estado de São Paulo.

Entrevista concedida em: 15/05/2015

\section{Para citar esta entrevista:}

DI PIERRO, Maria Clara. Educação de Jovens e Adultos no Brasil - Uma entrevista com a professora Maria Clara Di Pierro. [Entrevista realizada em 15 de maio de 2015]. Revista PerCursos. Florianópolis, v. 16, n.31, p. 245 - 255, maio/ago. 2015. Entrevistadora: Rita de Cássia Pacheco Gonçalves.

\section{DOI: $10.5965 / 1984724616312015245$}

http://dx.doi.org/10.5965/1984724616312015245 
PerCursos: Maria Clara, conta para nós, como você chegou nesse lugar, como pesquisadora de EJA? Tem alguma lembrança da infância, a Maria Clara, menina, adolescente, jovem... que sabores, cheiros viveu e que podem ter contribuído para ser uma pesquisadora referência em EJA?

Maria Clara: Trabalhar com educação, e com educação de adultos em particular, não foi algo planejado. Eu venho de uma família de classe média de ascendência italiana, meu pai era professor de matemática, minha mãe só estudou o primário. $O$ universo cultural dessa família era mais ou menos limitado, e a escolarização foi central na minha vida, porque alargou meu horizonte pessoal e cultural, e com base nessa experiência adquiri a convicção de que a escola pode cumprir esse papel para qualquer pessoa. Eu dei muita sorte, porque meu pai era um professor de matemática inovador, que trabalhou no ensino público e escolheu escolas experimentais para matricular os filhos. Eu comecei minha escolarização naquele período em que São Paulo desenvolvia experiências inovadoras em escolas públicas. Eu cursei o Grupo Escolar Experimental da Lapa e fiz a minha educação secundária no antigo Colégio de Aplicação da Faculdade de Filosofia, Letras e Ciências Humanas da USP, uma importante experiência de formação integral que transcendeu a bagagem cultural que minha família podia proporcionar. Quando concluí o secundário, tinha várias alternativas em mente, não sabia se queria cursar jornalismo, arquitetura, economia, e acabei optando pela geografia, devido a meus interesses pelas questões territorial e agrária, mas eu não pensava ser professora, pretendia trabalhar com planejamento. Frequentei a Universidade de São Paulo na segunda metade dos anos 70, no tempo da ditadura, me engajei no movimento estudantil, participei da reconstrução das entidades estudantis (DCE, UEE, UNE), experiência que foi muito importante na minha formação política. Eu trabalhava e estudava, me casei cedo com um colega do movimento estudantil, tive filho ainda durante a graduação, e nessa época comecei a ensinar, atividade que eu conseguia conciliar com os estudos, a maternidade e a militância. Desde o início, atuei na educação de jovens e adultos, pois foram as oportunidades que surgiram, sem que contudo tenha sido planejado. 


\section{PerCursos: E aí se apaixonou?}

Maria Clara: Aí me apaixonei e me engajei. Ensinei geografia por treze anos, durante o dia atuava com crianças e adolescentes e cuidava do meu filho, a noite dava aulas para jovens e adultos. Infelizmente minha experiência de docência no ensino público foi curta, com contrato precário, porque quando me formei passaram-se nove anos sem concurso para professor de geografia. Então eu trabalhei na rede particular, inclusive participei da oposição sindical. Nos anos 80 existiam em São Paulo cursos de educação de jovens e adultos na rede particular, em escolas com fins lucrativos e em projetos sociais de escolas confessionais. Eu ensinei jovens e adultos no Colégio Pinheiros, no Curso Supletivo Santa Inês, em uma escola da comunidade judaica - o Scholem Aleichem - e outra católica - o Colégio Santa Cruz -, onde atuei sob a direção do Sergio Haddad com um grupo de docentes jovens, motivados e inspirados pelo pensamento da educação popular.

Nessa época comecei um mestrado na USP sobre o ensino de geografia com jovens e adultos. Quando eu me interessei por fazer pesquisa, o Sergio Haddad me convidou para ser sua auxiliar no estado da arte no ensino supletivo ${ }^{1}$, que havia sido solicitado a ele pela Vanilda Paiva, que à época era dirigente do INEP. Era o ano de 1985, no momento da redemocratização. Fui trabalhar com o Sérgio nessa pesquisa, e foi assim que eu comecei a participar do grupo de educação popular do Centro Ecumênico de Documentação e Informação (CEDI), que na década seguinte daria origem à Ação Educativa. Continuei dando aulas no curso supletivo do Colégio Santa Cruz e fiquei muitos anos trabalhando nessa organização não governamental, em que se faz de tudo: se capta recursos, planeja, avalia, apoia movimentos, faz formação, faz pesquisa, prepara material didático, articula redes, incide em políticas públicas... O CEDI tinha gente trabalhando também com direitos humanos, indígenas, trabalhadores urbanos e rurais, pastorais das igrejas, questões ambientais, e essa convivência enriqueceu minha visão da sociedade brasileira, foi um espaço de intensa aprendizagem.

Eu tenho, então, uma experiência escolar de educação de adultos e outra como ativista e pesquisadora em organização não governamental (ONG). No Colégio Santa Cruz,

\footnotetext{
${ }^{1}$ HADDAD, Sérgio (coord.). Ensino supletivo no Brasil: estado da arte. Brasília: INEP, 1987. Disponível em http://www.dominiopublico.gov.br/download/texto/meo02519.pdf
} 
vivenciei uma formação pedagógica diferenciada porque desenvolvíamos um trabalho coletivo na perspectiva da educação popular. E o trabalho na ONG me colocou em contato com diversos movimentos sociais, com a luta pelo direito da educação de adultos, com a exigência de politicas públicas de qualidade. Eu tive uma experiência muito significativa no Acre ocidental, com seringueiros na Reserva Extrativista do Alto Juruá e, ao mesmo tempo, eu fiz formação de educadores de EJA na rede municipal de São Paulo; participei de articulações na gestão do Paulo Freire no município de São Paulo, da Rede de Apoio à Ação Alfabetizadora no Brasil (a RAAAB), do Consejo de Educación de Adultos de América Latina y el Caribe (o CEAAL), da preparação da V CONFINTEA e dos movimentos que levaram à articulação dos fóruns de EJA.

Assim, eu tenho treze anos de sala de aula, tenho quinze anos de atuação em ONGs, e depois desse ciclo eu pude fazer meu mestrado e doutorado em educação na PUC de São Paulo. No doutorado fiz um estágio com uma bolsa sanduiche no CREA da Universidade de Barcelona, na Espanha. Eu tive muitas oportunidades de formação e uma carreira que convergiu para a educação de adultos: da geografia eu fui para a educação de adultos, e do ensino eu fui para temática das políticas públicas, à qual me dediquei mais nas pesquisas. Comecei no mestrado investigando a política municipal de EJA de Porto Alegre no final dos anos $80^{2}$, pois no início da redemocratização apostávamos na descentralização, no município, no poder local com um espaço de gestão mais democrática e de inovação pedagógica, e a experiência da gestão do Olívio Dutra era uma referência inspiradora. Mas percebemos que se não houvesse uma política nacional não ia ser possível fazer mudanças importantes no âmbito local, então no doutorado eu fui estudar esse processo de construção das políticas públicas nacionais na redemocratização ${ }^{3}$.

\footnotetext{
${ }^{2}$ DI PIERRO, Maria Clara. Políticas municipais de educação básica de jovens e adultos no Brasil: estudo do caso de Porto Alegre (RS). São Paulo, PUCSP, 1996 (Dissertação de Mestrado em Educação).

${ }^{3}$ DI PIERRO, Maria Clara. As políticas de educação básica de jovens e adultos no Brasil no período 1985/1999. São Paulo, PUCSP, 2000 (Tese de Doutoramento em Educação).
} 
PerCursos: Dessa trajetória, vêm as suas pesquisas atuais? Quais são as pesquisas e reflexões que vêm animando seu trabalho atualmente?

Maria Clara:: Sou animada com a educação de jovens e adultos, mas numa atitude de resistência, porque estamos sempre remando contra a maré. Meu percurso de pesquisa seguiu as apostas políticas que fizemos ao longo do caminho. Minha pesquisa de mestrado refletia uma aposta no poder local e no município como um espaço de construção do direito e de modelos de atendimentos mais inovadores. Posteriormente a gente achou que era necessário institucionalizar e garantir esse direito no marco jurídico e na política nacional. Assim, no doutorado, fui historiar a luta para construir o direito à educação de adultos na Constituição de 88, na LDB de 96, nos planos de educação. Eu estudei o paradoxo da redemocratização nos anos 90, quando se construiu um marco jurídico favorável de garantia do direito à EJA nas leis, ao mesmo tempo em que foi o período em que a crise econômica e a hegemonia das orientações neoliberais desconstruíram esse direito nas políticas públicas. Minha pesquisa mostrou que, apesar da exclusão da EJA do FUNDEF durante o governo Fernando Henrique Cardoso, houve brechas para a educação de adultos. Então, analisei os três programas - o Alfabetização Solidária, o PRONERA e o PLANFOR -, buscando compreender as diferentes configurações de gestão da parceria nesses três programas, procurando interpretar a relação da sociedade civil com o Estado na produção da política pública nacional nos anos 90.

Posteriormente, eu fiz vários outros estudos sobre a relação da sociedade civil com o Estado, ou de avaliação de políticas públicas. Fizemos (a Ação Educativa em parceria com universidades) uma avaliação do primeiro ciclo do Programa Nacional de Educação na Reforma Agrária (PRONERA) por encomenda do INCRA nacional ${ }^{4}$. A última pesquisa que eu concluí foi sobre o impacto da inclusão da EJA no FUNDEB: nós vínhamos assinalando a ausência de financiamento da EJA como a questão crucial que limitava o desenvolvimento das políticas públicas de EJA, então a minha expectativa era que o FUNDEB viesse a criar as condições para um avanço na oferta de EJA ainda que não com

\footnotetext{
${ }^{4}$ DI PIERRO, M. C.; JESUS, S. M. S. A.; ANDRADE, M. R.; MOLINA, M. C. (Orgs.). A Educação na Reforma Agrária: Uma Avaliação do Programa Nacional de Educação na Reforma Agrária. São Paulo: Ação Educativa; Nead; Pronera/Incra/MDA, 2004.
} 
qualidade por conta de um fator de ponderação muito menor. Então eu desenhei uma pesquisa para avaliar o impacto do FUNDEB e, no primeiro momento, a minha expectativa era que fosse para avaliar um impacto positivo, mas quando eu consegui viabilizar a pesquisa, quando eu consegui financiamento e comecei a realizá-la, já estava configurado que o impacto não era o esperado. Então, já foi uma pesquisa para tentar compreender a razão pela qual, mesmo com o FUNDEB, a matrícula estava declinante. Eu analisei o estado de São Paulo, tomando o município como unidade principal de análise. Foi uma pesquisa com duas fases, uma quantitativa, com análise de banco de dados e uma qualitativa, de estudos de caso. Foi muito frustrante porque eu pensava que essa fase quantitativa fosse dar resultados, mas a qualidade dos dados sobre o financiamento era muito ruim, as bases de informação sobre o gasto na EJA não são fidedignas, então a primeira etapa da pesquisa deu poucas indicações. Na segunda fase, a qualitativa, fomos constatar nos municípios porque eles estavam gastando pouco, e percebemos que eles gastavam mais do que eles declaravam. Há uma subdeclaração nos sistemas de registro do gasto público, o gasto na EJA fica todo diluído na educação básica, você não consegue identificar o gasto específico ${ }^{5}$. Uma das principais recomendações desse estudo é que se reformule esse sistema de registro no gasto na EJA para melhorar o controle social, porém os gestores não querem fazer isso porque isso enrijece a execução do gasto. A verdade é que o FUNDEB trouxe recursos para os municípios, mas estes recursos não estão sendo gastos necessariamente na EJA. Isso me levou a concluir que precisamos mexer na cultura do direito à educação ao longo da vida. Os gestores vão se sentir obrigados a ofertar EJA se a sociedade também pressionar. Temos que trabalhar muito nessa questão do direito à EJA.

Eu saí dessa pesquisa um pouco sem esperanças, porque acho que estamos em uma fase bastante difícil. Tivemos, primeiro, uma institucionalização e uma ampliação do direito à EJA no plano jurídico. Hoje, a Emenda Constitucional 59 ampliou esse direito, não só para o ensino fundamental, mas também para o ensino médio. As diretrizes da educação nas

\footnotetext{
${ }^{5}$ DI PIERRO, M. C. O impacto da inclusão da Educação de Jovens e Adultos no Fundo de Manutenção e Desenvolvimento da Educação Básica (FUNDEB) no Estado de São Paulo. In: CATELLI JR., Roberto; HADDAD, Sérgio; RIBEIRO, Vera Masagão (Orgs.). A EJA em xeque: desafios das políticas de Educação de Jovens e Adultos no século XXI. São Paulo: Global; Ação Educativa, 2014, p. 39-76.
} 
prisões obrigam a oferta no sistema prisional; continuamos ampliando o direito na esfera jurídica. As políticas públicas garantiram as bases para uma oferta de educação básica para jovens e adultos pelas redes públicas de ensino. Então, hoje é diferente, tem financiamento, a escola que possui alunos com EJA tem um PDDE importante, que é o dinheiro direto na escola. Você tem livro didático na EJA, tem merenda, tem transporte. Hoje, a EJA está inserida na institucionalidade do sistema de educação básica, mas por não estar no sistema de avaliação, os maus resultados de aprendizagem, as nossas altas taxas de abandono e os baixos níveis de conclusão têm pouca visibilidade pública e pouca exigibilidade social sobre a qualidade da EJA. Ninguém acha que porque tem muitas crianças que não aprendem a ler no terceiro ano deva-se fechar a escola de criança. No entanto, no caso da EJA, os maus resultados levam ao fechamento das escolas. Os Municípios e Estados recebem recursos para o Plano de Desenvolvimento da Educação (PDE) e o único compromisso que eles assumem é manter um programa de alfabetização e nem isso eles fazem, mas o Ministério da Educação não deixa de lhes enviar os recursos. Então, temos que pressionar, fazer exigências. Nesse contexto adverso, que avança na declaração de direitos no plano jurídico e na institucionalização das políticas e ainda assim temos resultados insuficientes é de se perguntar: por que isso está ocorrendo? Por um complexo de questões. Mas a única brecha que eu vi nessa última pesquisa, nas redes municipais e estadual, foi naquelas escolas exclusivas de EJA, que oferecem EJA de manhã, tarde e noite, em geral com oferta mais flexível. Então, o projeto de pesquisa que eu estou desenvolvendo agora é de estudo dessas escolas, porque elas me parecem ser uma alternativa que pode ser uma resposta mais adequada. Esse modelo de EJA na escola regular, apenas noturna, com o professor sem preparação, esse modelo escolarizado do ensino supletivo que temos na maior parte das redes públicas, me parece divorciado das necessidades de aprendizagem e das condições de estudo dos jovens adultos. Eu acho que o paradigma compensatório ainda é hegemônico e a gente não conseguiu romper e ter um modelo de oferta específico. Por isso estou estudando essas escolas que são exclusivamente de EJA, para saber como elas estão respondendo as demandas de formação das pessoas, porque elas parecem ter mais procura e menos evasão. Uma das minhas hipóteses é de que esses centros estabilizam e colocam em formação 
permanente coletivos de professores e funcionários que estão pensando a EJA manhã, tarde e noite e, portanto, estão propensos a buscar respostas mais apropriadas tanto do ponto de vista curricular, quanto da organização escolar.

Estou completando 10 anos de USP, mas eu já tenho mais de 35 anos de vida profissional, e quero fechar minha carreira tentando buscar um sinal de esperança na EJA. Se eu conseguir fazer uma tese de livre docência, eu gostaria que ela pudesse fazer análise desse percurso de pesquisa ao longo dos últimos 30 anos, deixando não só uma interpretação crítica das políticas, mas também algo propositivo. Eu espero advogar a favor de uma escola exclusiva de adultos. Se eu hoje estivesse em um lugar de poder, eu iria apoiar os estados e municípios a criarem escolas exclusivas para educação de adultos porque me parece que essa está sendo a experiência mais promissora, muito mais que esses programas nacionais pré-moldados que têm sido as políticas nos últimos anos Brasil Alfabetizado, PRONERA, PROEJA, PRONATEC, PROJOVEM -, que são programas nacionais oferecidos aos estados e municípios como pacotes fechados, ou o governo local adere integralmente ou não recebe o recurso. Embora eu reconheça que a configuração e o desempenho desses programas sejam muito diferenciados, esse modo de articulação federativa dá pouca autonomia ao estado e município para ajustar o programa em seu contexto, seu objetivo e suas necessidades, e ao mesmo tempo, não garante uma institucionalização desses programas nas políticas. Mesmo os aspectos mais promissores e inovadores não se institucionalizam nas redes. Então, eu acredito que a gente tem que apostar num outro modelo de relação federativa para as políticas..

PerCursos: Você apontaria isso como o principal desafio para a EJA hoje? Que outros desafios você apontaria nesse momento?

Maria Clara: São muitos os desafios. Eu acho que buscar um regime de colaboração mais adequado entre União, Estados e Municípios é um deles. A União não pode renunciar ao seu papel indutor de políticas, mas esse padrão de programas pré-formatados que são oferecidos aos estados e municípios para adesão com pouquíssima flexibilidade acabaram gerando paralelismos e não ajudaram a institucionalizar e a fortalecer a EJA nas 
redes estaduais e municipais. Outro desafio para as políticas públicas e também para os movimentos sociais é produzir uma cultura do direito à educação dos jovens e adultos. A cultura do direito à educação na infância avançou no final do século XX, com diversos movimentos sociais e políticas, como o processo que levou à construção do Estatuto da Criança e do Adolescente, com a prioridade que o governo FHC deu para colocar todas as crianças na escola, com o FUNDEF e com o Bolsa Família. Mas ainda não se construiu, nem na sociedade cívil nem no Estado, uma cultura do direito à educação na idade adulta, acho que esse é um grande desafio. Outro desafio é a formação dos educadores, um território em que se está em débito. Vimos aqui neste VI Seminário de Formação de Educadores de EJA que, embora exista uma multiplicidade de iniciativas e práticas, e mesmo de políticas de formação, continuamos com os mesmos problemas de 20, 30 anos atrás. 0 diagnóstico de que falta formação aos educadores se reafirma apesar das leis que, desde o tempo do ensino supletivo, afirmam a necessidade de formação especifica para o educador de EJA. A gente não conseguiu modificar as estruturas das universidades para a formação inicial; as próprias diretrizes da formação docente não assimilaram a EJA como um eixo fundamental.

PerCursos: Você vê alguma chance para a EJA nessa discussão das diretrizes curriculares dos cursos de licenciatura?

Maria Clara: Eu acho que é mais um território de luta, porque não está dado. Se avançou muito, tanto no financiamento quanto na formação docente para a educação infantil e para a educação especial, mas não para a EJA. O PRONERA e o PRONACAMPO tiveram certa eficácia no sentido de criar as licenciaturas de educação no campo; o mesmo se pode dizer quanto à educação escolar indígena. A legislação sobre a inclusão da história e da cultura afro-brasileira e indígena no currículo escolar também está induzindo mudanças na formação docente. Não se pode dizer o mesmo com respeito à EJA. Acho necessário haver pelo menos uma disciplina obrigatória nos currículos da formação docente que aborde a EJA, mas temos que transversalizar os conteúdos relacionados a esse ciclo de vida na formação docente (em história, filosofia, psicologia, sociologia, didática e nos estágios), pois uma disciplina só não faz a formação. 
PerCursos: No currículo da UDESC, a EJA aparece nas ementas de várias disciplinas, mas os professores não conhecem a EJA, então não tratam de EJA?

Maria Clara: Realmente a abordagem da EJA nas diferentes disciplinas das licenciaturas é muito limitada; é preciso trabalhar muito para transversalizar esse conteúdo nos currículos. Sou favorável a uma indução do Conselho Nacional de Educação, como ocorreu com a obrigatoriedade do ensino de Libras ou com a história e cultura afrobrasileira e indígena.

PerCursos: Poderia ser uma função dos fóruns lutar pela obrigatoriedade de disciplinas de EJA nos currículos das licenciaturas?

Maria Clara: Sim. É preciso que a CAPES e o Conselho Nacional de Educação incorporem a EJA nas diretrizes e na avaliação da formação docente, de modo a colocar o problema para as faculdades de educação. Mas, é claro, isso só vai acontecer e ter repercussão se houver um movimento de reivindicação e cobrança que cumpre aos fóruns impulsionar.

PerCursos: Nesse cenário, na sua experiência, a sua participação nos fóruns sempre foi muito forte; como você vê o papel do fórum, especialmente agora nesse momento da EJA?

Maria Clara: Eu participei dos movimentos e articulações na preparação da V CONFINTEA Conferência Internacional de Educação de Adultos (que ocorreu em Hamburgo, em 1997), que culminaram na criação dos fóruns e realização periódica dos Encontros Nacionais, os ENEJAs. Em um primeiro momento, o movimento dos fóruns eclodiu, assumiu um protagonismo e cumpriu um papel de resistência às políticas educacionais adversas para a EJA quando o governo FHC optou pela focalização dos recursos, com a meta de colocar todas as crianças de 7 a 14 anos na escola. Foi uma abordagem pouco sistêmica que excluiu os outros níveis e modalidades das prioridades das políticas educacionais. No governo Lula a EJA voltou para a agenda da política pública do governo federal. Os fóruns influíram nas políticas, foram reconhecidos e apoiados, tiveram um auge no momento da 
preparação da CONFINTEA VI realizada em Belém do Pará, em 2009. A partir de então, os fóruns vivem um momento de certa perplexidade, crise de identidade e falta de estratégia política. Mas eu acho que os fóruns podem recuperar um papel importante se conseguirem estabelecer algumas prioridades e atuar como movimento em torno de algumas campanhas, como a isonomia no financiamento da EJA no FUNDEB e a flexibilização dos modelos curriculares.

PerCursos: Muito obrigada!.

Recebida em: 31/05/2015 Aprovada em: 15/06/2015

Universidade do Estado de Santa Catarina - UDESC Centro de Ciências Humanas e da Educação - FAED Revista PerCursos Volume 16 - Número 31 - Ano 2015 revistapercursos@gmail.com 